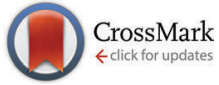

Cite this: Phys. Chem. Chem. Phys., 2015, 17, 18318

Received 18th January 2015, Accepted 18th May 2015 DOI: $10.1039 / c 5 c p 00315 f$

www.rsc.org/pccp

\title{
Revealing highly unbalanced energy barriers in the extension and contraction of the muscle-like motion of a [c2]daisy chain $\dagger$
}

\author{
Yan-Ling Zhao, ${ }^{* a}$ Rui-Qin Zhang, ${ }^{b}$ Christian Minot, $^{\text {ac }}$ Klaus Hermann ${ }^{d}$ and \\ Michel A. Van Hove
}

\begin{abstract}
Nanoscale muscle-like materials have aroused great interest as they may provide controllable mechanical operations by artificial actuations. Molecular designs to achieve the desired motion at the macroscopic scale in experiments require atomic level understanding. By systematic quantum chemical and molecular dynamics calculations we reveal that the length change is not only due to the linear telescoping from the dibenzo[24]crown-8 recognition at two docking stations but also the folding/unfolding of two bulky stoppers. The extension and contraction processes of a [c2]daisy chain under acidic vs. basic conditions are exothermic but need to cross very different energy barriers, being at least double the height under acidic compared to basic conditions, hindering balanced cyclic motions at moderate excitation. Our result suggests that to realize the desired muscle-like motion one should adopt sufficiently high external excitation, using for example reasonably high temperature and further optimizing the solution used.
\end{abstract}

\section{Introduction}

Biomimetic research harnesses nature's creations to guide us in developing new valuable products. Hence, muscle-like materials are envisaged to provide controllable mechanical operations in a variety of environments, from benign to hostile. In accordance with the bottom-up principle, design and synthesis at the molecular level are fundamentally conducive to creating precise molecular machines and then intentionally amplifying their action to the macro-scale. Chemists have synthesized several muscle-like molecular shuttles, where one functional group reciprocates between two fixed "stations" along the axis under external stimuli such as a chemical environment, ${ }^{1-5}$ electrochemical redox reactions, ${ }^{1,6-13}$ or illumination. ${ }^{8,14-19}$ Notably, Sauvage et $a .^{20}$ first synthesized a doubly threaded rotaxane capable of contraction and stretching under the action of a chemical stimulus due to exchanging $\mathrm{Cu}^{+} / \mathrm{Zn}^{2+}$ in solution. This opens a research arena to synthesize complex molecular shuttles in functional analogy with natural muscles.

\footnotetext{
${ }^{a}$ Institute of Computational and Theoretical Studies \& Department of Physics, Hong Kong Baptist University, Hong Kong, China. E-mail: ylzhao2008@gmail.com

${ }^{b}$ Department of Physics and Materials Science, City University of Hong Kong, Hong Kong, China

${ }^{c}$ Laboratoire de Chimie Théorique, Université Pierre \& Marie Curie - Paris 6, CNRS, UMR7616, case 137, 4 place Jussieu 75252 Paris Cedex 05, France

${ }^{d}$ Inorganic Chemistry Department, Fritz-Haber-Institut der Max-Planck-Gesellschaft, Faradayweg 4-6, 14195 Berlin, Germany

$\dagger$ Electronic supplementary information (ESI) available. See DOI: 10.1039/c5cp00315f
}

Recently, the Giuseppone ${ }^{21}$ group has successfully polymerized doubly threaded rotaxanes and in principle can thereby magnify the elongation/contraction of the individual units by a factor of $\sim 3000$. The Stoddart ${ }^{22}$ group highlighted this work afterwards. As shown in Fig. 1a, each half of the rotaxane polymer unit consists mainly of five components, (1) a rod-shaped backbone, (2) a dibenzo[24]crown-8 (DB24C8) ring-like ether, (3) a docking station that can vary between a secondary dialkylammonium ion $\left(\mathrm{NH}_{2}{ }^{+}\right)$in a low $\mathrm{pH}$ environment and a neutral amino group $(\mathrm{NH})$ in high $\mathrm{pH},(4)$ a triazolium cation docking station, and (5) a terpyridine end group. The length of each unit varies dynamically as the binding affinity of DB24C8 to the $\mathrm{NH}_{2}{ }^{+} / \mathrm{NH}$ docking station changes with $\mathrm{pH}$ : with a solution of trifluoroacetic acid, the DB24C8 ring preferentially forms hydrogen bonds with $\mathrm{NH}_{2}{ }^{+}$, $c f$. Fig. $1 \mathrm{~b} ;{ }^{23-27}$ in contrast, under a basic solution of sodium hydroxide, the DB24C8 ring prefers to combine with the triazolium cation docking station, as the $\mathrm{NH}_{2}{ }^{+}$is neutralized to $\mathrm{NH}, c f$. Fig. 1c. Therefore, the pH of the environment determines which of these two docking stations is favored, allowing alternation between contracted and extended states by cycling between high and low $\mathrm{pH}$, which also provides the needed energy. For polymerization, ${ }^{21} c f$. Fig. 1d, two terpyridine groups of two rotaxanes are 6-fold coordinated to a single $\mathrm{Fe}^{2+}$ ion (originating from $\mathrm{FeCl}_{2}$ present in the solution), so as to connect the units head to tail and form a snake-like linear polymer. As revealed by light scattering and small-angle neutron scattering measurements, ${ }^{21}$ the unit lengths in the extended and contracted forms are found to be $c a .5 .4$ and $3.2 \mathrm{~nm}$, respectively. 


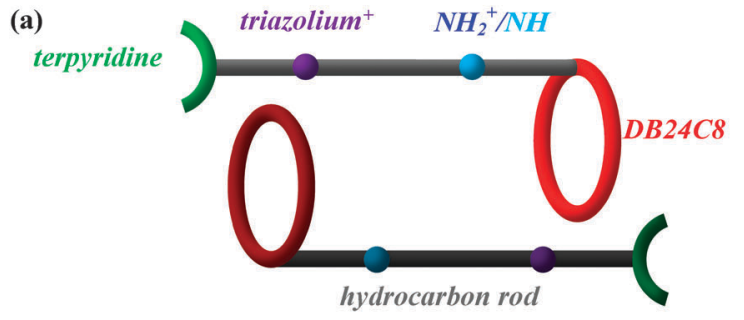

(b)

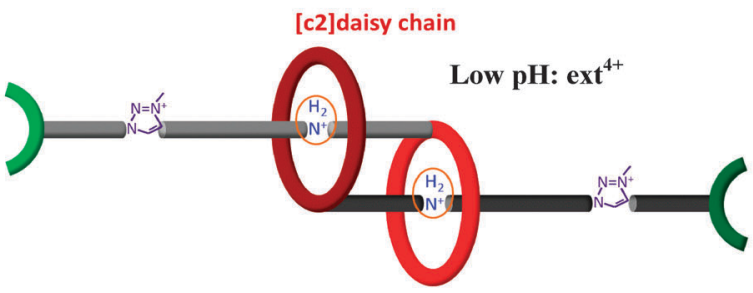

(c)

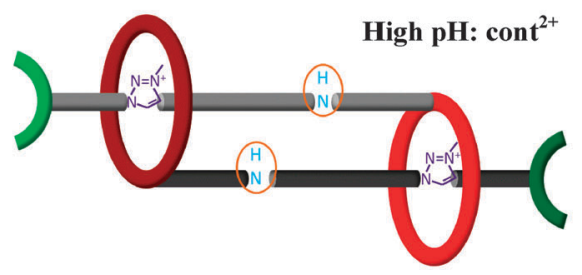

(d)

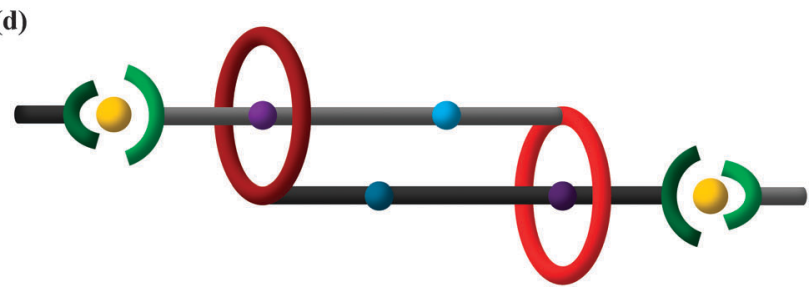

Fig. 1 Schematic representations of the muscle-like [c2]daisy chain polymer (a) Each half of the doubly threaded rotaxane polymer unit consists of a hydrocarbon rod with two docking stations, a crown ether ring DB24C8, and a terpyridine end group; (b) two identical halves are mutually threaded into a [c2]daisy chain, docked at the $\mathrm{NH}_{2}{ }^{+}$station (in low pH) in the extended state and (c) at the triazolium ${ }^{+}$station (in high $\mathrm{pH}$ ) in the contracted state; (d) polymerized [c2]daisy chains are linked by $\mathrm{Fe}^{2+}$ (yellow balls), held by terpyridine groups, and docked in the contracted state.

The $2.2 \mathrm{~nm}$ length difference in each unit is amplified in a linear polymer of about 3000 units to cause a stretch from about 9400 to about $15900 \mathrm{~nm}$, thus hopefully realizing the muscle-like motion in a quasi-macroscopic regime.

However, many challenging problems still exist in going from the laboratory setting to practical molecular machines. The study of the structural evolution presenting a macroscopic muscle-like motion is very demanding. By means of mass spectrometry, ${ }^{1} \mathrm{H}$ NMR, UV-Vis spectra, and scattering techniques, experimental studies have successfully identified the synthesized functional groups, tracked the configuration variations under the external stimuli, and extracted the polymer size and shape. With quantum mechanical calculations, performed for the first time for this system, we herein add deeper insight into the mechanisms of such a muscle-like material at an atomic level which can help design future molecular machines. Our calculations contribute useful insight by presenting the equilibrated end configurations as well intermediate configurations of the rotaxane unit of the polymer obtained by Giuseppone et al., ${ }^{21}$ and analyze detailed potential energy profiles as well as structural evolution during contraction and stretching, thus aiming to identify the functioning mechanisms and to provide important thermodynamic data. Solvent effects are taken into account to show the impact of the environment on the motion.

\section{Models and computational details}

Generally, a rotaxane is a dumbbell-like molecule that is threaded through a macrocycle ring which can move along the molecule's shaft without being able to escape due to bulky end groups. In this work, each half of the doubly threaded rotaxane provides the other one with a crown ether ring, allowing mutual threading which affords the freedom of linear contraction and stretching while preventing dethreading. Such a type of rotaxane possesses a reciprocal symmetry and is often called a [c2]daisy chain, where "c" stands for cyclic and " 2 " stands for a two-membered chain (as opposed to, for example, an [a3]daisy chain for an acyclic threemembered chain). ${ }^{28}$

The initial model is built manually from the structure shown in Fig. 1 of ref. 22, in agreement with the molecular formula reported in the supporting information of ref. 21. The acidic environment of the [c2]daisy chain is simulated in the present study by adding two protons near the nitrogen of its amino groups, leading to an extended structure in acid. For the basic environment of the [c2]daisy chain the two protons of $\mathrm{NH}_{2}{ }^{+}$are assumed to be neutralized by $\mathrm{OH}^{-}$ions and, thus, are left out of the simulation which results in the contracted structure in base. Hereafter, the extended and contracted forms are respectively designated as ext ${ }^{4+}$ and cont ${ }^{2+}$. The configuration ext ${ }^{4+}$ $\left(\mathrm{C}_{116} \mathrm{H}_{134} \mathrm{O}_{16} \mathrm{~N}_{14}\right)$ carries four positive charges localized at two $\mathrm{NH}_{2}^{+}$ and two triazolium cations, while the two positive charges of cont ${ }^{2+}$ $\left(\mathrm{C}_{116} \mathrm{H}_{132} \mathrm{O}_{16} \mathrm{~N}_{14}\right)$ localize at two triazolium cations.

The [c2]daisy chains are self-assembled groups of molecules held together by weak bonds, mainly hydrogen bonds, van der Waals (vdW) interactions, electrostatic interactions, and/or coupling by $\pi-\pi$ stacking. At present, many theoretical approaches include long-range dispersion forces to model such weak interactions. ${ }^{29-32}$ In this work, we chose the self-consistent-charge densityfunctional tight-binding (SCC-DFTB) method $^{33,34}$ to carry out most calculations where dispersion contributions are included via Lennard-Jones potentials to describe the universal force field parameters. The SCC-DFTB method uses linear combinations of frozen atomic orbitals to represent electrons that are delocalized over the entire system. Corresponding interaction integrals for pairs of atomic orbitals are calculated separately and used when evaluating self-consistent molecular orbitals of a given system. The SCC-DFTB method has proven to be both computationally efficient for very large systems and accurate when compared with standard DFT results for electronic and geometric configurations as well as energies. Therefore, it is extensively employed to deal with large clusters containing hundreds of atoms, and particularly suitable for those consisting mainly of $\mathrm{C}, \mathrm{H}, \mathrm{O}$, and $\mathrm{N}$ atoms. ${ }^{35-39}$ 
To investigate the solvent effect on the [c2]daisy chain, we perform SCC-DFTB-D-based molecular dynamics (SCC-DFTB-D/MD) simulations for a period of $1 \mathrm{ps}$. The canonical ensemble is adopted with an Anderson thermostat in an $N V T$ model for a temperature of $300 \mathrm{~K}$. The time step is set at $1 \mathrm{fs}$ for the integration of the equations of motion by a Verlet velocity algorithm. Periodic boundary conditions are used with a unit cell defined by $a=6.6 \mathrm{~nm}, b=3.3 \mathrm{~nm}$, $c=2.7 \mathrm{~nm}$, and $\alpha=\beta=\gamma=90^{\circ}$. After the [c2]daisy chain was placed in the center of the box the remaining space is filled with 413 acetonitrile $\left(\mathrm{CH}_{3} \mathrm{CN}\right)$ molecules, which are randomly distributed and automatically generated with the help of the Gromacs package ${ }^{40}$ by checking overlaps of Coulomb and vdW radii.

In order to obtain more accurate binding energies, energy profiles, dipole moments and electrostatic potential (ESP) distributions, single-point calculations on the [c2]daisy chain supramolecules are carried out by using the $\omega \mathrm{B} 97 \mathrm{XD} / 6-31 \mathrm{G}^{* *}$ level of theory, which also considers the dispersion correction and is included in the G09 package. ${ }^{41}$ The SMD solvation model ${ }^{42}$ is adopted as we describe the energy profiles in solution. In the experiment, the cationic [c2]daisy chain was synthesized in an ionic liquid, where stoichiometric $\mathrm{PF}_{6}^{-}$counterions accompany the supramolecules to neutralize the charge in the environment of organic solvents. Thus, the role of solvation is considered for binding with $\mathrm{PF}_{6}{ }^{-}$counterions. Optimization and frequency calculations on smaller species such as $\mathrm{PF}_{6}{ }^{-}, \mathrm{CH}_{3} \mathrm{CN}$, and chloroform $\left(\mathrm{CHCl}_{3}\right)$, and $\mathrm{PF}_{6}{ }^{-}\left(\mathrm{CH}_{3} \mathrm{CN}\right)_{n}(n=1-8)$ and $\mathrm{PF}_{6}{ }^{-}\left(\mathrm{CHCl}_{3}\right)_{n}(n=1-8)$ complexes are performed at the same calculation level.

\section{Results and discussion}

\section{Equilibria and intermediates}

We here analyze in detail the contraction/extension cycle of the [c2]daisy chain. When the equilibrated ext ${ }^{4+}$ is exposed to an alkaline solution ( $c f$. the schematic diagram in Fig. 2), two protons (one from each of the two $\mathrm{NH}_{2}{ }^{+}$groups) rapidly leave, leading to an intermediate which we call deproton-ext ${ }^{2+}$. This intermediate then gradually evolves to the final equilibrated form of cont ${ }^{2+}$ in basic solution. When cont ${ }^{2+}$ encounters an acidic environment, two protons attach to two neutral NH groups, generating the proton-cont ${ }^{4+}$ intermediate, which then evolves back into the equilibrated form of ext $^{4+}$ in acid. This cycle repeats as the solution is switched back and forth between basic and acidic conditions. The two equilibration processes of this cycle are:

Contraction in base: deproton-ext ${ }^{2+} \rightarrow$ cont $^{2+}$

$$
\text { Stretching in acid: proton-cont }{ }^{4+} \rightarrow \mathrm{ext}^{4+}
$$

An extensive conformation search for the favorable intermediates and equilibria was carried out by SCC-DFTB-D optimizations in the vacuum without any position constraints. It resulted in the two equilibrated forms and two intermediates that are shown in Fig. 2 to illustrate their cyclic transformations. Fig. S1 ( $c f$. ESI $\dagger$ ) shows the geometric details of the two equilibrium structures more clearly, identifying those atoms that are essential for the formation of equilibrium geometries.
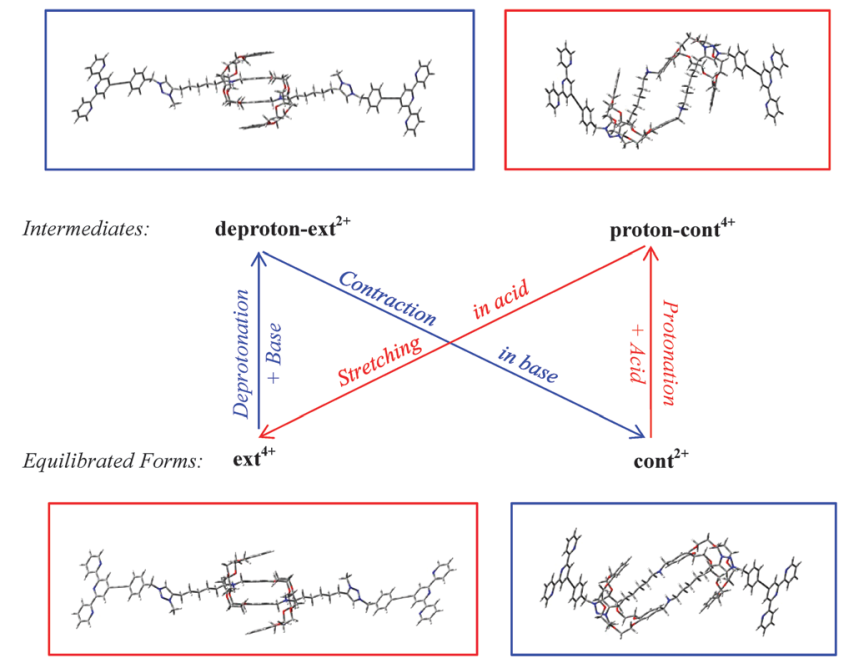

Fig. 2 The cyclic process of acid-induced extension and base-promoted contraction through equilibrium and intermediate structures, from SCCDFTB-D optimizations in the vacuum. The central schematic shows the cycle in a simplified energy diagram, with equilibrated forms detailed below and intermediates above. Gray, white, red, and blue atom colors represent $\mathrm{C}, \mathrm{H}, \mathrm{O}$, and $\mathrm{N}$, respectively.

The configuration ext $^{4+}$ has a long thin shape after complete relaxation. Its central part is dominated by a four-level $\pi-\pi$ stacking of four phenol rings with separations of $1.047 \mathrm{~nm}$ between the most distant rings and $0.324 \mathrm{~nm}$ between the two central parallel-displaced rings; it also exhibits four hydrogen bonds between $\mathrm{NH}_{2}{ }^{+}$and DB24C8 of type $\mathrm{N}-\mathrm{H} \cdots \mathrm{O}$ with $\mathrm{H} \cdots \mathrm{O}$ distances of 0.209 and $0.207 \mathrm{~nm}$, and of type $\mathrm{N}^{+}-\mathrm{H} \cdots \mathrm{O}$ with $\mathrm{H} \cdots \mathrm{O}$ distances of 0.181 and $0.181 \mathrm{~nm}$. To validate the SCC-DFTB-D results, we have also optimized the DB24C8 and $\mathrm{NH}_{2}{ }^{+}$interacting part of ext $^{4+}$ by $\omega \mathrm{B} 97 \mathrm{XD} / 6-31 \mathrm{G}^{* *}$ (with the triazolium parts and two stoppers removed to reduce the computational cost). It turns out that the central interlayer spacing is about $0.316 \mathrm{~nm}$, close to the $0.324 \mathrm{~nm}$ found by SCC-DFTB-D. Additionally, as compared with the interlayer distance ( 0.35 to $0.40 \mathrm{~nm}$ ) of $\pi-\pi$ stacking between two benzenes in previous DFT studies, ${ }^{29-32}$ this shows that four hydrogen bonds between $\mathrm{NH}_{2}{ }^{+}$and DB24C8 and more layered benzene rings will help strengthen the group in the central part of ext ${ }^{4+}$. The configuration cont ${ }^{2+}$ presents a short thick shape with the triazolium cations staying outside the two DB24C8 rings and perpendicular to the dibenzo planes. Five $\mathrm{C}-\mathrm{H} \cdots \mathrm{O}$ hydrogen bonds are found on one side with $\mathrm{H}$. . O distances from 0.217 to $0.245 \mathrm{~nm}$, due to the hydrogen atoms from triazolium and hydrocarbons near the crown ether oxygen.

To evaluate the amount of telescoping which takes place between the two forms, we first consider the distance between two oxygen atoms (O1 and O2, labeled in Fig. S1a and f, ESI $\dagger$ ) of the respective crown ether rings: the $\mathrm{O} 1-\mathrm{O} 2$ distances are $0.91 \mathrm{~nm}$ for ext ${ }^{4+}$ and $1.70 \mathrm{~nm}$ for cont ${ }^{2+}$. A difference of $0.79 \mathrm{~nm}$ is much smaller than the experimental value $2.2 \mathrm{~nm}$, which suggests that the telescoping between two threads only accounts for a part of the length change in the full [c2]daisy chain. Thus, other contributions affecting its length change must exist. 
If we examine the individual left and right halves of one unit in Fig. S1c, d, h and i (ESI $\dagger$ ), we clearly observe the planar rigidity of the bulky stoppers, each composed of a terpyridine group together with its adjacent ethinyl and phenyl species. In ext $^{4+}$, these bulky stoppers are slightly folded away from the long axis of the [c2]daisy chain, while in cont ${ }^{2+}$, they are strongly folded back around the crown ether rings. As shown in Fig. S1e and j (ESI $\dagger$ ), the dihedral angles for the chain of atoms C1-C2-C3-N4, which are highlighted by enlarged balls, are $139.6^{\circ}$ and $85.0^{\circ}$ for ext $^{4+}$ and cont ${ }^{2+}$, respectively. This folding greatly decreases the total length of the contracted form: we measure the distances between two $\mathrm{N}$ atoms of the central pyridines at the two ends (which are used for polymerization) as $3.23 \mathrm{~nm}$ for cont ${ }^{2+}$ but $4.82 \mathrm{~nm}$ for ext ${ }^{4+}$. We thus see that the folding of the rigid end groups actually contributes substantially to the expansion/ contraction, in addition to the mutual telescoping of the two linear chains.

As shown in Fig. 2, the structure of the intermediate deproton$\mathrm{ext}^{2+}$ is similar to that of $\mathrm{ext}^{4+}$, while the other intermediate proton-cont ${ }^{4+}$ has a relatively large distortion as compared with cont $^{2+}$. To confirm the stability of the [c2]daisy chain in these four supramolecules, we have calculated the frozen binding energy $\left(\Delta E_{\mathrm{b}}\right)$ between the two halves. Here "frozen" means that the optimized geometries of the paired halves are kept unchanged when they are separated. The frozen binding energy is calculated as: $\Delta E_{\mathrm{b}}=E_{\text {tot }}([\mathrm{c} 2]$ daisy chain $)-\left[E_{\text {tot }}(\right.$ left half $)+E_{\text {tot }}($ right half $\left.)\right]$. The single point total energy of the [c2]daisy chain is calculated with the basis set superposition error (BSSE) correction at the level of $\omega \mathrm{B} 97 \mathrm{XD} / 6-31 \mathrm{G}^{* *}$. As listed in Table 1 , the two more negative $\Delta E_{\mathrm{b}}$ values $\left(-67.33\right.$ and $-110.97 \mathrm{kcal} \mathrm{mol}^{-1}$ ) reflect the thermodynamic stability of the equilibrated structures ext ${ }^{4+}$ and cont ${ }^{2+}$. The two less negative $\Delta E_{\mathrm{b}}$ values $\left(-13.83\right.$ and $\left.-40.70 \mathrm{kcal} \mathrm{mol}^{-1}\right)$ reasonably imply the relative instability of the intermediates proton-cont ${ }^{4+}$ and deproton-ext ${ }^{2+}$ as starting points towards the equilibrium states during the muscle-like motion. cont ${ }^{2+}$ and deproton-ext ${ }^{2+}$ are more stable than ext $^{4+}$ and protoncont $^{4+}$, respectively. We ascribe this difference to the crowding into a smaller space of the two $\mathrm{NH}_{2}{ }^{+}$groups of ext ${ }^{4+}$ and proton$\operatorname{cont}^{4+}$ : their two extra positive charges generate more Coulomb repulsion and higher interior strain energy. Additionally, the ten $\mathrm{C}-\mathrm{H} \cdots \mathrm{O}$ hydrogen bonds in cont ${ }^{2+}$ further improve their stability, even though the $\mathrm{C}-\mathrm{H} \cdots \mathrm{O}$ hydrogen bond is usually weaker than the $\mathrm{N}-\mathrm{H} \cdots \mathrm{O}$ hydrogen bond. ${ }^{4-45}$

\section{Energy profiles and structural evolutions in the vacuum}

In this section, we analyze the detailed potential energy profiles during two muscle-like movements and track the structural evolution during the back-and-forth sliding of the DB24C8 rings between the docking stations provided by the $\mathrm{NH}_{2}^{+} / \mathrm{NH}$ and triazolium cations. We first study the situation in the vacuum by SCC-DFTB-D constrained geometry optimizations. We progressively slide one half of an isolated [c2]daisy chain relative to the other by imposing and freezing a sequence of distances between two pairs of $\mathrm{O}$ atoms in the two DB24C8 rings: $\mathrm{O} 1$ and $\mathrm{O} 2$, as well as $\mathrm{O} 3$ and $\mathrm{O} 4$ (which are in principle equivalent by symmetry to $\mathrm{O} 1$ and $\mathrm{O} 2$, respectively, see Fig. S1b, ESI $\dagger$ ). At each O1-O2
Table 1 Dipole moments and BSSE-corrected binding energies calculated by $\omega \mathrm{B} 97 \mathrm{XD} / 6-31 \mathrm{G}^{* *}$

\begin{tabular}{|c|c|c|}
\hline Items & $\mu$ (Debye) & BSSE- $\Delta E_{\mathrm{b}}\left(\mathrm{kcal} \mathrm{mol}^{-1}\right)$ \\
\hline$\overline{\text { ext }^{4+}}$ & 2.50 & -67.33 \\
\hline Proton-cont ${ }^{4+}$ & 5.70 & -13.83 \\
\hline $\operatorname{cont}^{2+}$ & 1.35 & -110.97 \\
\hline Deproton-ext ${ }^{2+}$ & 1.42 & -40.70 \\
\hline $\mathrm{PF}_{6}^{-}$ & 0 & - \\
\hline $\mathrm{CH}_{3} \mathrm{CN}$ & $3.90\left(3.92^{47}\right)$ & - \\
\hline $\mathrm{CHCl}_{3}$ & $1.30\left(1.01^{47}\right)$ & - \\
\hline $\mathrm{PF}_{6}^{-}\left(\mathrm{CH}_{3} \mathrm{CN}\right)$ & 0.59 & -10.44 \\
\hline $\mathrm{PF}_{6}^{-}\left(\mathrm{CH}_{3} \mathrm{CN}\right)_{2}$ & 0.00 & -19.81 \\
\hline $\mathrm{PF}_{6}^{-}\left(\mathrm{CH}_{3} \mathrm{CN}\right)_{3}$ & 1.69 & -27.13 \\
\hline $\mathrm{PF}_{6}^{-}\left(\mathrm{CH}_{3} \mathrm{CN}\right)_{4}$ & 0.78 & -33.80 \\
\hline $\mathrm{PF}_{6}^{-}\left(\mathrm{CH}_{3} \mathrm{CN}\right)_{5}$ & 2.27 & -38.67 \\
\hline $\mathrm{PF}_{6}^{-}\left(\mathrm{CH}_{3} \mathrm{CN}\right)_{6}$ & 0.00 & -44.05 \\
\hline $\mathrm{PF}_{6}^{-}\left(\mathrm{CH}_{3} \mathrm{CN}\right)_{7}$ & 2.99 & -51.89 \\
\hline $\mathrm{PF}_{6}^{-}\left(\mathrm{CH}_{3} \mathrm{CN}\right)_{8}$ & 0.02 & -57.96 \\
\hline $\mathrm{PF}_{6}^{-}\left(\mathrm{CHCl}_{3}\right)$ & 5.71 & -10.67 \\
\hline $\mathrm{PF}_{6}{ }^{-}\left(\mathrm{CHCl}_{3}\right)_{2}$ & 0.063 & -20.26 \\
\hline $\mathrm{PF}_{6}^{-}\left(\mathrm{CHCl}_{3}\right)_{3}$ & 3.59 & -27.64 \\
\hline $\mathrm{PF}_{6}^{-}\left(\mathrm{CHCl}_{3}\right)_{4}$ & 1.14 & -35.81 \\
\hline $\mathrm{PF}_{6}^{-}\left(\mathrm{CHCl}_{3}\right)_{5}$ & 1.75 & -42.33 \\
\hline $\mathrm{PF}_{6}{ }^{-}\left(\mathrm{CHCl}_{3}\right)_{6}$ & 0.81 & -49.02 \\
\hline $\mathrm{PF}_{6}^{-}\left(\mathrm{CHCl}_{3}\right)_{7}$ & 0.33 & -54.65 \\
\hline $\mathrm{PF}_{6}-\left(\mathrm{CHCl}_{3}\right)_{8}$ & 0.86 & -61.88 \\
\hline
\end{tabular}

distance, which is varied in steps of about $0.05 \mathrm{~nm}$, we optimize the positions of all other atoms and obtain the total energy by SCC-DFTB-D calculations. This allows us to track the total energy and structural change as a function of the O1-O2 distance, which represents the ring-ring distance, as shown in Fig. 3. Note that increasing the $\mathrm{O} 1-\mathrm{O} 2$ distance corresponds to contracting the [c2]daisy chain, and vice versa. It should be mentioned that the present constrained search is approximate and cannot completely exclude the existence of alternative equilibration paths. However, it can provide a reasonable qualitative thermodynamic description of the muscle-like motion.

On the basis of the constrained geometries, we also perform single point energy calculations at the level of $\omega \mathrm{B} 97 \mathrm{XD} / 6-31 \mathrm{G}^{* *}$ to obtain an energy profile comparison between the supramolecule in acid and in base, and between two methods. The energy data are shown in Tables S1 and S2 (ESI $\dagger$ ). Fig. 3a displays energy profiles for the stretching in acid (red dashed curve, right to left) and contraction in base (blue dashed curve, left to right) in the vacuum, starting from the intermediates discussed earlier. We find by $\omega \mathrm{B} 97 \mathrm{XD}$ that, in the vacuum, the contraction must surmount a barrier of $7.0 \mathrm{kcal} \mathrm{mol}^{-1}$ before descending to a net total energy of $-62.2 \mathrm{kcal} \mathrm{mol}^{-1}$, while the stretching experiences a barrier of $14.6 \mathrm{kcal} \mathrm{mol}^{-1}$ and a net total energy decrease of $-52.8 \mathrm{kcal} \mathrm{mol}^{-1}$. We note that both barriers are comparable to the thermal energy at room temperature $\left(0.6 \mathrm{kcal} \mathrm{mol}^{-1}\right)$ and can thus be overcome by thermal fluctuations. The barrier for stretching is about twice that for contraction. Such an asymmetry implies different kinetic constants and different response velocities under external acid vs. base stimuli: stretching should be significantly slower than contraction. Merely from the viewpoint of conformational changes without temperature and solvent 

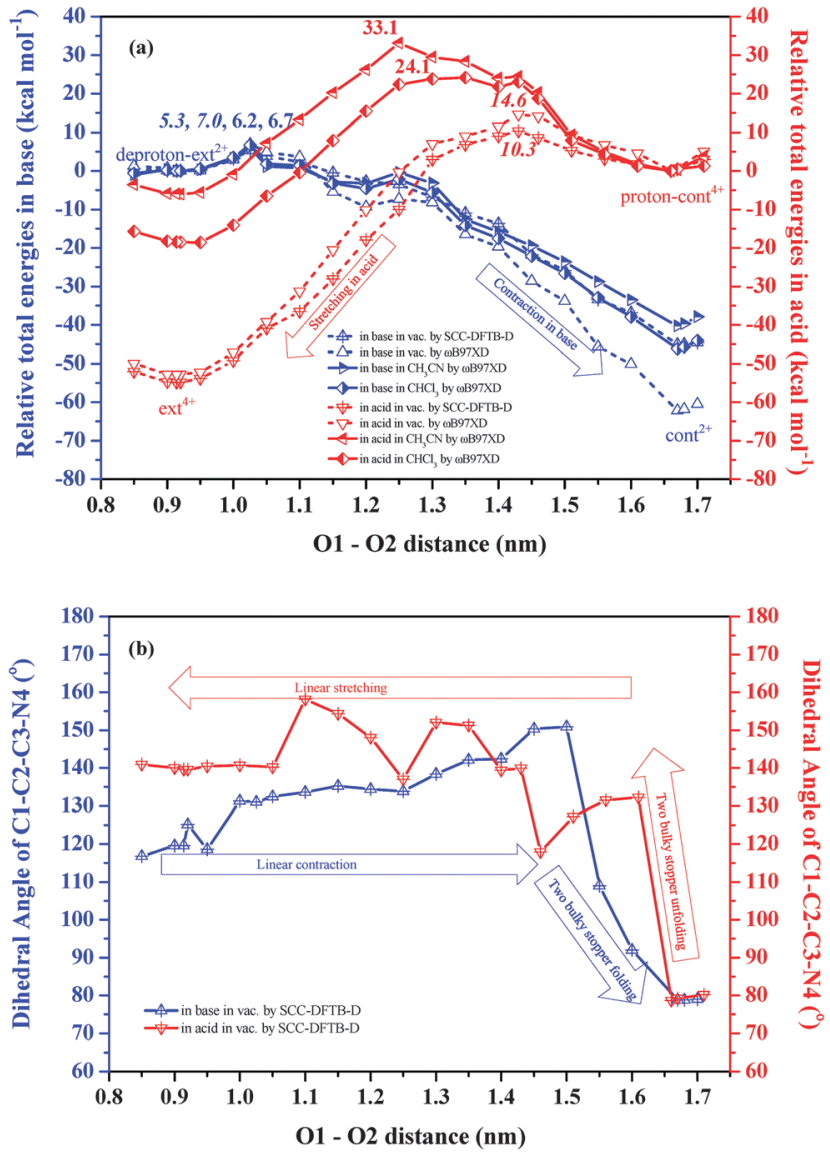

Fig. 3 (a) Relative total energy profiles in the vacuum by SCC-DFTB-D constrained geometry optimizations and by $\omega B$ 97XD/6-31G** single point calculations and in solutions by $\omega B$ 97XD/6-31G** single point calculations with the consideration of the SMD solvent model of $\mathrm{CH}_{3} \mathrm{CN} / \mathrm{CHCl}_{3}$, as labeled in the graph (numbers are barrier energies, italicized in vacuum, otherwise in solution), and (b) evolution of the dihedral angle between the backbone (rod) and the rigid bulky stopper by SCC-DFTB-D constrained geometry optimizations in the vacuum as a function of the $\mathrm{O} 1-\mathrm{O} 2$ distance (note that the overall length of the [c2]daisy chain decreases when the O1-O2 distance increases, and vice versa). The contraction of the [c2]daisy chain is shown in blue, while expansion is shown in red, following the arrows' directions.

effects, the large total energy decrease $\left(-62.2\right.$ and $\left.-52.8 \mathrm{kcal} \mathrm{mol}^{-1}\right)$ from the intermediates to the equilibrated structures, following relatively small barriers, is very suitable for muscle-like motion: while thermal energy can overcome these barriers and trigger the equilibration after a $\mathrm{pH}$ change, the motion can then not easily be reversed before the $\mathrm{pH}$ itself is reversed. Moreover, we find that the stretching barrier $\left(10.3 \mathrm{kcal} \mathrm{mol}^{-1}\right)$ by SCC-DFTB-D is also two times that for contraction $\left(5.3 \mathrm{kcal} \mathrm{mol}^{-1}\right)$, which supports the validity of total energies predicted by this semiempirical method.

An animation (Movie S1) showing our detailed model of the full contraction and elongation cycle of the [c2] daisy chain is available in the ESI. $\dagger$ The relative total energies and dihedral angles are listed in Tables S1 and S2 of the ESI. $\dagger$ Selected frames are shown in Fig. S2 (ESI $\dagger$ ). Before the contraction process, the $\mathrm{O} 1-\mathrm{O} 2$ distance of deproton-ext ${ }^{2+}$ is about $0.91 \mathrm{~nm}$. As the $\mathrm{O} 1-\mathrm{O} 2$ distance increases, the total energy of the conformation rises until reaching the barrier at $1.03 \mathrm{~nm}$ where the transition state is reached (see Frame $5_{\mathrm{b}}$ in Fig. S2, ESI $\dagger$ ). The barrier is due to breaking the four-layered $\pi-\pi$ stacking in the central part of the [c2]daisy chain. The geometry changes little from deproton-ext ${ }^{2+}$ to the barrier. In contrast, the initial stretching process from cont $^{2+}$ (see Fig. S1f, ESI $\dagger$ ) has already shown large structural changes in going to the intermediate (see Frame $1_{\mathrm{a}}$ ). The backbones of the two chains (rods in Fig. 1) arch away from each other due to the Coulomb repulsion between two $\mathrm{NH}_{2}{ }^{+}$ions. As a result, the transition state (see Frame $7_{\mathrm{a}}$ ) appears at a relatively larger $\mathrm{O} 1-\mathrm{O} 2$ distance of $1.43 \mathrm{~nm}$. The geometry at the barrier is quite different from the starting structure proton-cont ${ }^{4+}$ and already close to that of ext ${ }^{4+}$. The energy barrier caused by structural deformation is now mainly due to the DB24C8 rings breaking loosely from the triazolium cations. Hence, the stretching in acid should be more difficult and slower than the contraction in base.

One key reason for different barriers in contraction $v s$. extension is the folding of two bulky stoppers occurring in the last phase of contraction, which contrasts with the unfolding in the first phase of stretching. This change can be described by the dihedral angle between the backbone and the bulky stopper within each half, as sketched in Fig. S1e and $\mathrm{j}$ (ESI $\dagger$ ). We measure this dihedral angle for the chain of atoms C1-C2-C3-N4 to track the folding and unfolding of the bulky stoppers as a function of the $\mathrm{O} 1-\mathrm{O} 2$ distance. As shown in Fig. 3b, for the contraction in base, when the $\mathrm{O} 1-\mathrm{O} 2$ distance grows toward $1.50 \mathrm{~nm}$, the dihedral angle gradually increases from $\sim 120^{\circ}$ to $\sim 150^{\circ}$. The configuration change in this process originates mainly from the [c2]daisy chain linear contraction. When the $\mathrm{O} 1-\mathrm{O} 2$ distance exceeds $1.50 \mathrm{~nm}$, the dihedral angle rapidly decreases to $\sim 80^{\circ}$, reflecting the folding of the two bulky stoppers until the final cont $^{2+}$ is produced. For the stretching in acid, the dihedral angle at first rapidly increases from $\sim 80^{\circ}$ to $\sim 130^{\circ}$ as the $\mathrm{O} 1-\mathrm{O} 2$ distance is reduced from $1.67 \mathrm{~nm}$ to $1.61 \mathrm{~nm}$, indicating that the two bulky stoppers are quickly unfolding. Afterwards, the dihedral angle steps up and down, until by $1.05 \mathrm{~nm}$ its value stabilizes at $\sim 140^{\circ}$. In particular, in the 1.61-1.46 nm range, we find that the molecule is trying to encapsulate the $\mathrm{NH}_{2}{ }^{+}$into the DB24C8 ring (see Frame $6_{\mathrm{a}}$ ). Accordingly, due to the DB24C8 covering $\mathrm{NH}_{2}{ }^{+}$, the large deformation generates a higher barrier for stretching than contraction. After $1.43 \mathrm{~nm}$, the process corresponds to the smooth stretching of the [c2]daisy chain until ext $^{4+}$ is formed. In this phase, the hydrogen bonds of $\mathrm{N}-\mathrm{H} \cdots \mathrm{O} / \mathrm{N}^{+}-\mathrm{H} \cdots \mathrm{O}$ and $\pi-\pi$ stacking among phenol rings are formed, which also impacts the dihedral angle between the backbone and the bulky stopper.

\section{Solvent effects}

Experimentally, the muscle-like polymer was synthesized in a solution of $\mathrm{CH}_{3} \mathrm{CN}$ and $\mathrm{CHCl}_{3}$ with a mixing ratio of $1: 1$. $^{21}$ Therefore, we have also evaluated the [c2]daisy chain thermal energy data in an SMD solvation model by $\omega \mathrm{B} 97 \mathrm{XD} / 6-31 \mathrm{G}^{* *}$. The results are included in Fig. 3a (full lines). Clearly, the stretching barriers in both solutions (33.1 and $24.1 \mathrm{kcal} \mathrm{mol}^{-1}$ in $\mathrm{CH}_{3} \mathrm{CN}$ and $\mathrm{CHCl}_{3}$ ) are much higher than in the vacuum $\left(14.6 \mathrm{kcal} \mathrm{mol}^{-1}\right)$ and at the same time the reaction heats in 
solution $\left(-6.0\right.$ and $-18.6 \mathrm{kcal} \mathrm{mol}{ }^{-1}$ in $\mathrm{CH}_{3} \mathrm{CN}$ and $\left.\mathrm{CHCl}_{3}\right)$ become much smaller than in the vacuum $\left(-52.8 \mathrm{kcal} \mathrm{mol}^{-1}\right)$. This clearly means that the solvents will significantly hinder the stretching movement in acid. In contrast, the solvent effect on the contraction in base is rather small with energy profiles similar to the vacuum in the initial part of the path but becoming somewhat different in the final stage. Altogether, in solvents the contraction barriers for a single [c2]daisy chain are found to be much lower than those for stretching, analogous to the results in the vacuum which confirms that stretching will be slower than contraction. The acid-promoted elongation of the polymer may thus also occur during the cyclic muscle-like motion.

To further clarify the solvent effect on the contraction and stretching processes, we first perform the SCC-DFTB-D/MD simulations by two equilibrium configurations and two intermediate states in an environment of 413 molecules of $\mathrm{CH}_{3} \mathrm{CN}$. Here we only discuss $\mathrm{CH}_{3} \mathrm{CN}$ as a typical model of the solution environment. After $1 \mathrm{ps}$, the four configurations remain almost the same as in the vacuum, as compared visually in Fig. 4. This means that the [c2]daisy chain in these four states is well stabilized in the organic solvents. As shown in Table S3 (ESI $\dagger$ ), in the final $100 \mathrm{fs}$, the root mean square deviation (RMSD) around room temperature is 3.9 to $5.5 \mathrm{~K}$ and the RMSD of the potential energy is 25 to $31 \mathrm{kcal} \mathrm{mol}^{-1}$. We assume that the system has reached equilibrium at this stage. According to the average potential energies calculated in the last $100 \mathrm{fs}$, the two reaction heats in solution are $-32.0 \mathrm{kcal} \mathrm{mol}^{-1}$ for the contraction and $-12.1 \mathrm{kcal} \mathrm{mol}^{-1}$ for the stretching, as listed in Table 2. Compared with the results in the vacuum via full atom relaxations and constrained geometry optimization by SCCDFTB-D, it is found that the energy differences in the solution are significantly reduced, especially for the stretching process.

We believe that the dominant effect resulting in energy differences in acid as compared to base solution is due to unequal electrostatic interactions of the cationic [c2]daisy chain with polar solvents. An opposite example indirectly justifies this speculation. As reported in a recent study, ${ }^{46}$ the free-energy landscape of a similar but neutral [c2]daisy chain rotaxane shows nearly equal energy barriers for both contraction and extension processes, with values of $13.65 \pm 0.04 \mathrm{kcal} \mathrm{mol}^{-1}$ derived from ${ }^{1} \mathrm{H}$ NMR at $228 \mathrm{~K}$ in a solution of $\mathrm{CDCl}_{3}$. Therefore, we have calculated and compared corresponding dipole moments,

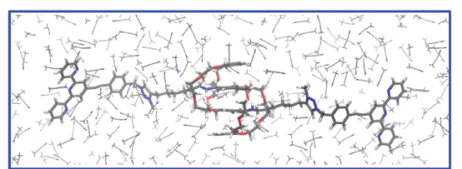

deproton-ext $\mathrm{t}^{2+}$

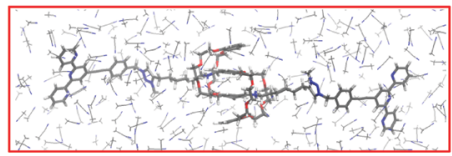

$\mathbf{e x t}^{4+}$

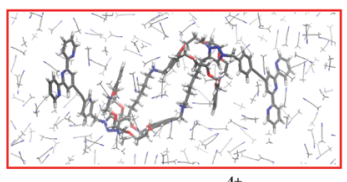

proton-cont $t^{4+}$

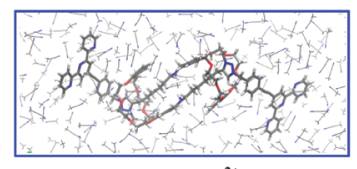

$\operatorname{cont}^{2+}$
Fig. 4 SCC-DFTB-D/MD frames of two equilibria and two intermediates at $1 \mathrm{ps}$ in an environment of $413 \mathrm{CH}_{3} \mathrm{CN}$ molecules.
Table 2 Reaction heat comparisons from SCC-DFTB-D calculations, by full optimization in the vacuum, constrained optimization in the vacuum (with four fixed $\mathrm{O}$ atoms) and molecular dynamics by NVT in solution (unit: kcal mol-1)

\begin{tabular}{llll}
\hline & $\Delta E$ (full & \multicolumn{2}{c}{$\Delta E$ (four O fixed } \\
Muscle-like motion & opt. in vac.) & opt. in vac.) & $\Delta E$ (NVT in sol.) \\
\hline Contraction in base & -46.8 & -45.1 & -32.0 \\
Stretching in acid & -49.9 & -54.9 & -12.1
\end{tabular}

$\mu$, of four [c2]daisy chains. As shown in Table 1, the $\mu$ values are in the order cont ${ }^{2+}<$ deproton-ext ${ }^{2+}<$ ext $^{4+}<$ proton-cont $^{4+}$. The $\mu$ of proton-cont ${ }^{4+}$ is rather high. Thus, we may expect that the potential energy of proton-cont ${ }^{4+}$ will be dramatically decreased in solution so as to reduce the reaction heat and simultaneously increase the energy barrier during the stretching process. Fig. 5a-d display the ESP distributions of the four supramolecules on the vdW surface, defined at an electron density of $0.001 \mathrm{e} \mathrm{Bohr}^{-3}$. Ranging from -125.5 to $+125.5 \mathrm{kcal} \mathrm{mol}^{-1}$, a stronger ESP distribution (dark blue) is found from proton-cont ${ }^{4+}$ to ext $^{4+}$ and a milder spread (mostly light blue) is observed from deproton-ext ${ }^{2+}$ to cont $^{2+}$. This implies again that the solvent effects during the stretching process will be stronger than during contraction. Additionally, the two bulky stoppers of these supramolecules are found to have smaller ESP values than the central sections. Although the ESP in the center is strongly impacted by solvents, the two ends still have greater opportunities to undergo a polymerization reaction with $\mathrm{Fe}^{2+}$ cations.

Last, we have to consider the effect of solvation on the $\mathrm{PF}_{6}{ }^{-}$ counterions that are present experimentally in the solvent to neutralize the charges of the [c2]daisy chains. In fact, we find that flexible combinations between small ions like $\mathrm{PF}_{6}{ }^{-}$and solvent molecules can easily occur, i.e., solvents could reduce the direct contact between $\mathrm{PF}_{6}{ }^{-}$and [c2] daisy chain cations. At the level of $\omega \mathrm{B} 97 \mathrm{XD} / 6-31 \mathrm{G}^{* *}$, stable configurations of $\mathrm{PF}_{6}{ }^{-}\left(\mathrm{CH}_{3} \mathrm{CN}\right)_{n}$ or $\mathrm{PF}_{6}{ }^{-}\left(\mathrm{CHCl}_{3}\right)_{n}(n=1-8)$ complexes are found, see Fig. S3 (ESI $\left.\dagger\right)$, which are confirmed to have no imaginary frequencies. They belong to weak $\mathrm{C}-\mathrm{H} \cdots \mathrm{F}$ hydrogen bonding complexes, where two or three $\mathrm{H} \cdots \mathrm{F}$ distances within $0.30 \mathrm{~nm}$ are formed between each solvent molecule and $\mathrm{PF}_{6}{ }^{-}$. As listed in Table 1, the BSSE$\Delta E_{\mathrm{b}}$ values in these complexes can reach up to $-62 \mathrm{kcal} \mathrm{mol}^{-1}$, which indicate favorable aggregations between $\mathrm{PF}_{6}{ }^{-}$and solvents. More importantly, the ESP of $\mathrm{PF}_{6}{ }^{-}$can be significantly reduced after binding with $\mathrm{CH}_{3} \mathrm{CN}$ or $\mathrm{CHCl}_{3}$ molecules, judging from the changes illustrated in Fig. 5e-h. Without solvents, a direct contact of $\mathrm{PF}_{6}{ }^{-}$will strongly distort the cationic [c2]daisy chain, especially the extended form, and likely result in losing the muscle-like function, according to our tests on the direct interaction between the [c2]daisy chain and $\mathrm{PF}_{6}{ }^{-}$by $\mathrm{PM} 6$ semi-empirical optimizations. Our cations in the [c2]daisy chain are not expected to exhibit a strong Coulomb interaction with $\mathrm{PF}_{6}{ }^{-}$. The solvents provide a soft negative ESP environment for supramolecules to avoid strong electrostatic interactions between the [c2]daisy chain and surrounding $\mathrm{PF}_{6}{ }^{-}$and keep the [c2]daisy chain in a working state during the muscle-like motion. 


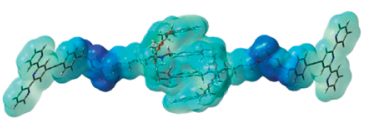

(a) deproton-ext ${ }^{2+}$

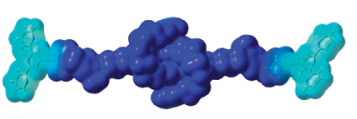

(c) $\mathrm{ext}^{4+}$

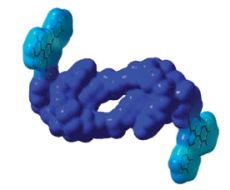

(b) proton-cont ${ }^{4+}$

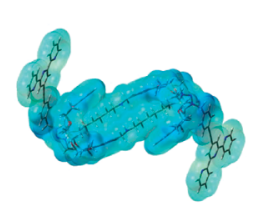

(d) cont $^{2+}$
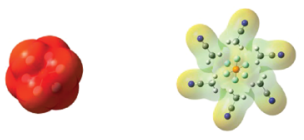

(e) $\mathrm{PF}_{6}$

(f) $\mathrm{PF}_{6}{ }_{6}\left(\mathrm{CH}_{3} \mathrm{CN}\right)_{6}$

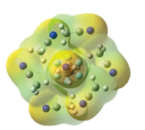

(g) $\mathrm{PF}_{6}{ }^{-}\left(\mathrm{CH}_{3} \mathrm{CN}\right)_{8}$

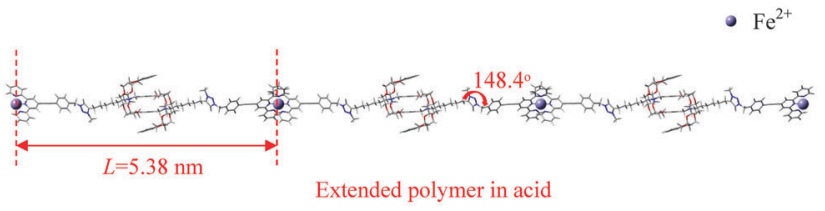

羃IT总

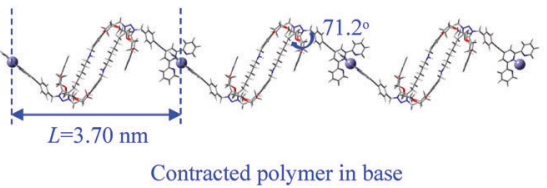

Fig. 6 The extended vs. contracted polymer (i.e. Fe ${ }^{2+}$-linked [c2]daisy chains) confirmed by SCC-DFTB-D geometry and cell optimizations. The repeat length of the polymer unit $L$ and dihedral angle $\mathrm{C} 1-\mathrm{C} 2-\mathrm{C} 3-\mathrm{N} 4$ are labeled in red and blue, resp.

repeatedly inject acid or base with the concomitant accumulation of waste products and consumption of new energy. In a natural muscle also, it is the chemical energy that is being converted into mechanical energy which is not accounted for by the present simulation.

\section{Summary and remarks}

In summary, at the atomic level, we have given a detailed description of how a highly promising rotaxane executes muscle-like mechanical motion under acidic vs. basic conditions. We determine its equilibrated and intermediate forms and find that the change in length comes from two main mechanisms: the back-and-forth telescoping of the DB24C8 rings between $\mathrm{NH}_{2}{ }^{+}$and triazolium ionic docking sites, as proposed in the literature, and also, to a significant extent, the folding $v s$. unfolding of two bulky stoppers; $\pi-\pi$ stacking and multiple hydrogen bonds as well contribute to the stabilization of the energetics of the process. We present activated exothermic processes for both the expansion and the contraction by evaluating the corresponding energy barriers.

The stretching is found to be more difficult and slower than the contraction as determined by the highly unequal energy barriers and reaction heats in the vacuum and in solution, electrostatic potential distributions, and dipole moment comparison. The difference occurs in the particular protonated contraction intermediate, which undergoes a large conformation distortion and has a strong interaction with solvents due to its large dipole moment. In addition, by studying weak hydrogen bonding complexes between $\mathrm{PF}_{6}{ }^{-}$and $\mathrm{CH}_{3} \mathrm{CN} / \mathrm{CHCl}_{3}$, we conclude that solvation plays an important role in effectively reducing the strong electrostatic interactions between [c2] daisy chain cations and $\mathrm{PF}_{6}{ }^{-}$counterions and provides a soft polar environment for the muscle-like motion of the [c2]daisy chain polymer. Our understanding can be helpful to enable the desired muscle-like motion at a larger length scale in experiments with sufficiently high external excitation using for example reasonably high temperature and further optimized solution. 


\section{Acknowledgements}

We thank the High Performance Cluster Computing Centre, Hong Kong Baptist University, which receives funding from the Research Grants Council, University Grants Committee of the HKSAR and HKBU. This work is supported in part by project no. 9041650 of the Research Grants Council of HKSAR. MAVH and YLZ were supported in part by the HKBU Strategic Development Fund. CM acknowledges support from HKBU's Sabbatical Visitor scheme and partial support from the HKBU Strategic Development Fund. KH acknowledges support from HKBU's Distinguished Scholar scheme and partial support from the HKBU Strategic Development Fund.

\section{References}

1 R. A. Bissell, E. Córdova, A. E. Kaifer and J. F. Stoddart, Nature, 1994, 369, 133-137.

2 M.-V. Martínez-Díaz, N. Spencer and J. F. Stoddart, Angew. Chem., Int. Ed. Engl., 1997, 36, 1904-1907.

3 P. R. Ashton, R. Ballardini, V. Balzani, I. Baxter, A. Credi, M. C. T. Fyfe, M. T. Gandolfi, M. Gómez-López, M.-V. Martínez-Díaz, A. Piersanti, N. Spencer, J. F. Stoddart, M. Venturi, A. J. P. White and D. J. Williams, J. Am. Chem. Soc., 1998, 120, 11932-11942.

4 P. G. Clark, M. W. Day and R. H. Grubbs, J. Am. Chem. Soc., 2009, 131, 13631-13633.

5 Z. Zhang, C. Han, G. Yu and F. Huang, Chem. Sci., 2012, 3, 3026-3031.

6 P. Gaviña and J.-P. Sauvage, Tetrahedron Lett., 1997, 38, 3521-3524.

7 L. Raehm, J.-M. Kern and J.-P. Sauvage, Chem. - Eur. J., 1999, 5, 3310-3317.

8 N. Armaroli, V. Balzani, J.-P. Collin, P. Gaviña, J.-P. Sauvage and B. Ventura, J. Am. Chem. Soc., 1999, 121, 4397-4408.

9 R. Ballardini, V. Balzani, W. Dehaen, A. E. Dell'Erba, F. M. Raymo, J. F. Stoddart and M. Venturi, Eur. J. Org. Chem., 2000, 591-602.

10 J.-P. Collin, C. Dietrich-Buchecker, P. Gaviña, M. C. JimenezMolero and J.-P. Sauvage, Acc. Chem. Res., 2001, 34, 477-487.

11 Y. Liu, A. H. Flood, P. A. Bonvallet, S. A. Vignon, B. H. Northrop, H.-R. Tseng, J. O. Jeppesen, T. J. Huang, B. Brough, M. Baller, S. Magonov, S. D. Solares, W. A. Goddard, C.-M. Ho and J. F. Stoddart, J. Am. Chem. Soc., 2005, 127, 9745-9759.

12 S. Saha, A. H. Flood, J. F. Stoddart, S. Impellizzeri, S. Silvi, M. Venturi and A. Credi, J. Am. Chem. Soc., 2007, 129, 12159-12171.

13 G. Fioravanti, N. Haraszkiewicz, E. R. Kay, S. M. Mendoza, C. Bruno, M. Marcaccio, P. G. Wiering, F. Paolucci, P. Rudolf, A. M. Brouwer and D. A. Leigh, J. Am. Chem. Soc., 2008, 130, 2593-2601.

14 A. C. Benniston and A. Harriman, Angew. Chem., Int. Ed. Engl., 1993, 32, 1459-1461.

15 A. C. Benniston, A. Harriman and V. M. Lynch, Tetrahedron Lett., 1994, 35, 1473-1476.
16 H. Murakami, A. Kawabuchi, K. Kotoo, M. Kunitake and N. Nakashima, J. Am. Chem. Soc., 1997, 119, 7605-7606.

17 P. R. Ashton, R. Ballardini, V. Balzani, A. Credi, K. R. Dress, E. Ishow, C. J. Kleverlaan, O. Kocian, J. A. Preece, N. Spencer, J. F. Stoddart, M. Venturi and S. Wenger, Chem. - Eur. J., 2000, 6, 3558-3574.

18 A. Harada, Acc. Chem. Res., 2001, 34, 456-464.

19 R. E. Dawson, S. F. Lincoln and C. J. Easton, Chem. Commun., 2008, 3980-3982.

20 M. C. Jiménez, C. Dietrich-Buchecker and J.-P. Sauvage, Angew. Chem., Int. Ed., 2000, 39, 3284-3287.

21 G. Du, E. Moulin, N. Jouault, E. Buhler and N. Giuseppone, Angew. Chem., Int. Ed., 2012, 51, 12504-12508.

22 C. J. Bruns and J. F. Stoddart, Nat. Nanotechnol., 2013, 8, 9-10.

23 J. Wu, K. C.-F. Leung, D. Benítez, J.-Y. Han, S. J. Cantrill, L. Fang and J. F. Stoddart, Angew. Chem., Int. Ed., 2008, 47, 7470-7474.

24 L. Fang, M. Hmadeh, J. Wu, M. A. Olson, J. M. Spruell, A. Trabolsi, Y.-W. Yang, M. Elhabiri, A.-M. Albrecht-Gary and J. F. Stoddart, J. Am. Chem. Soc., 2009, 131, 7126-7134.

25 C.-J. Chuang, W.-S. Li, C.-C. Lai, Y.-H. Liu, S.-M. Peng, I. Chao and S.-H. Chiu, Org. Lett., 2009, 11, 385-388.

26 Y. Jiang, J.-B. Guo and C.-F. Chen, Org. Lett., 2010, 12, 4248-4251.

27 M. Hmadeh, L. Fang, A. Trabolsi, M. Elhabiri, A.-M. Albrecht-Gary and J. F. Stoddart, J. Mater. Chem., 2010, 20, 3422-3430.

28 P. R. Ashton, I. Baxter, S. J. Cantrill, M. C. T. Fyfe, P. T. Glink, J. F. Stoddart, A. J. P. White and D. J. Williams, Angew. Chem., Int. Ed., 1998, 37, 1294-1297.

29 M. O. Sinnokrot and C. D. Sherrill, J. Phys. Chem. A, 2004, 108, 10200-10207.

30 M. P. Waller, A. Robertazzi, J. A. Platts, D. E. Hibbs and P. A. Williams, J. Comput. Chem., 2006, 27, 491-504.

31 J.-D. Chai and M. Head-Gordon, Phys. Chem. Chem. Phys., 2008, 10, 6615-6620.

32 R. M. Parrish and C. D. Sherrill, J. Am. Chem. Soc., 2014, 136, 17386-17389.

33 G. Seifert, J. Phys. Chem. A, 2007, 111, 5609-5613.

34 B. Aradi, B. Hourahine and T. Frauenheim, J. Phys. Chem. A, 2007, 111, 5678-5684.

35 D. Porezag, T. Frauenheim, T. Köhler, G. Seifert and R. Kaschner, Phys. Rev. B: Condens. Matter Mater. Phys., 1995, 51, 12947-12957.

36 M. Elstner, D. Porezag, G. Jungnickel, J. Elsner, M. Haugk, T. Frauenheim, S. Suhai and G. Seifert, Phys. Rev. B: Condens. Matter Mater. Phys., 1998, 58, 7260-7268.

37 T. Frauenheim, G. Seifert, M. Elstner, Z. Hajnal, G. Jungnickel, D. Porezag, S. Suhai and R. Scholz, Phys. Status Solidi B, 2000, 217, 41-62.

38 M. Elstner, T. Frauenheim, E. Kaxiras, G. Seifert and S. Suhai, Phys. Status Solidi B, 2000, 217, 357-376.

39 T. Frauenheim, G. Seifert, M. Elstner, T. Niehaus, C. Köhler, M. Amkreutz, M. Sternberg, Z. Hajnal, A. D. Carlo and S. Suhai, J. Phys.: Condens. Matter, 2002, 14, 3015-3047. 
40 E. Lindahl, B. Hess and D. van der Spoel, J. Mol. Model., 2001, 7, 306-317.

41 M. J. Frisch, G. W. Trucks, H. B. Schlegel, G. E. Scuseria, M. A. Robb, J. R. Cheeseman, G. Scalmani, V. Barone, B. Mennucci, G. A. Petersson, H. Nakatsuji, M. Caricato, X. Li, H. P. Hratchian, A. F. Izmaylov, J. Bloino, G. Zheng, J. L. Sonnenberg, M. Hada, M. Ehara, K. Toyota, R. Fukuda, J. Hasegawa, M. Ishida, T. Nakajima, Y. Honda, O. Kitao, H. Nakai, T. Vreven, J. A. Montgomery, Jr., J. E. Peralta, F. Ogliaro, M. Bearpark, J. J. Heyd, E. Brothers, K. N. Kudin, V. N. Staroverov, R. Kobayashi, J. Normand, K. Raghavachari, A. Rendell, J. C. Burant, S. S. Iyengar, J. Tomasi, M. Cossi, N. Rega, J. M. Millam, M. Klene, J. E. Knox, J. B. Cross, V. Bakken, C. Adamo, J. Jaramillo, R. Gomperts, R. E. Stratmann, O. Yazyev, A. J. Austin, R. Cammi, C. Pomelli, J. W. Ochterski, R. L. Martin, K. Morokuma, V. G. Zakrzewski,
G. A. Voth, P. Salvador, J. J. Dannenberg, S. Dapprich, A. D. Daniels, Ö. Farkas, J. B. Foresman, J. V. Ortiz, J. Cioslowski and D. J. Fox, Gaussian 09, Revision C.01, Gaussian, Inc., Wallingford, CT, 2009.

42 A. V. Marenich, C. J. Cramer and D. G. Truhlar, J. Phys. Chem. B, 2009, 113, 6378-6396.

43 G. R. Desiraju and B. N. Murty, Chem. Phys. Lett., 1987, 139, 360-361.

44 F. H. Allen, J. A. K. Howard, V. J. Hoy, G. R. Desiraju, D. S. Reddy and C. C. Wilson, J. Am. Chem. Soc., 1996, 118, 4081-4084.

45 G. R. Desiraju, Acc. Chem. Res., 1996, 29, 441-449.

46 C. J. Bruns, J. Li, M. Frasconi, S. T. Schneebeli, J. Iehl, H.-P. J. de Rouville, S. I. Stupp, G. A. Voth and J. F. Stoddart, Angew. Chem., Int. Ed., 2014, 53, 1953-1958.

47 R. D. Nelson, Jr., D. R. Lide and A. A. Maryott, NSRDS-NBS 10, 1967. 